\title{
Protocol
}

\section{Injection of dsRNA into Drosophila Embryos for RNA Interference (RNAi)}

\author{
Leonie Misquitta, Qin Wei, and Bruce M. Paterson
}

This protocol was adapted from "Targeted Disruption of Gene Function in Drosophila by RNA Interference," Chapter 19, in Drosophila Protocols (eds. Sullivan et al.). Cold Spring Harbor Laboratory Press, Cold Spring Harbor, NY, USA, 2000. Please note that this version of the protocol is a 2008 revision.

\section{INTRODUCTION}

RNA interference (RNAi) is a powerful method for determining the role of specific genes during Drosophila embryogenesis. This protocol describes a technique by which Drosophila embryos can be injected with dsRNA in order to disrupt targeted gene function. The approach is straightforward, utilizing improved methods for injecting the dsRNA directly through the chorion of the embryo. This strategy minimizes problems normally associated with desiccation of the dechorionated embryo and facilitates post-injection analysis of gene expression.

\section{RELATED INFORMATION}

This issue of CSH Protocols contains several related articles. The double-stranded RNA needed for RNAi is prepared as in Preparation of Double-Stranded RNA for Drosophila RNA Interference (RNAi). Embryos are collected shortly before injection [typically, 30-60 min prior; see Collection of Drosophila Embryos for RNA Interference (RNAi)]. This injection technique can also be used for generating transgenic Drosophila lines, as in Drosophila RNA Interference (RNAi) Using a Gal-4 Inducible Transgene Vector (Misquitta et al. 2008). These procedures assume that the investigator has access to a working fly facility and is familiar with basic methods for injection of embryos and the analysis of gene expression in Drosophila embryos. If not, details for these procedures can be found elsewhere; see Ashburner (1989a,b); for microinjection procedures, see Kiehart et al. (2000).

\section{MATERIALS}

CAUTIONS AND RECIPES: Please see Appendices for appropriate handling of materials marked with $\langle$ ! $>$, and recipes for reagents marked with $<\mathbf{R}>$.

\section{Reagents}

dsRNA mixed with filtered food dye, from Step 15 of Preparation of Double-Stranded RNA for Drosophila RNA Interference (RNAi)

Embryos arrayed and dried onto glass slides, from Collection of Drosophila Embryos for RNA Interference (RNAi)

\section{Equipment}

Capillaries (glass; Frederick Haer and Co.)

These capillaries are fiber-filled, which helps in fluid movement within the needle. 


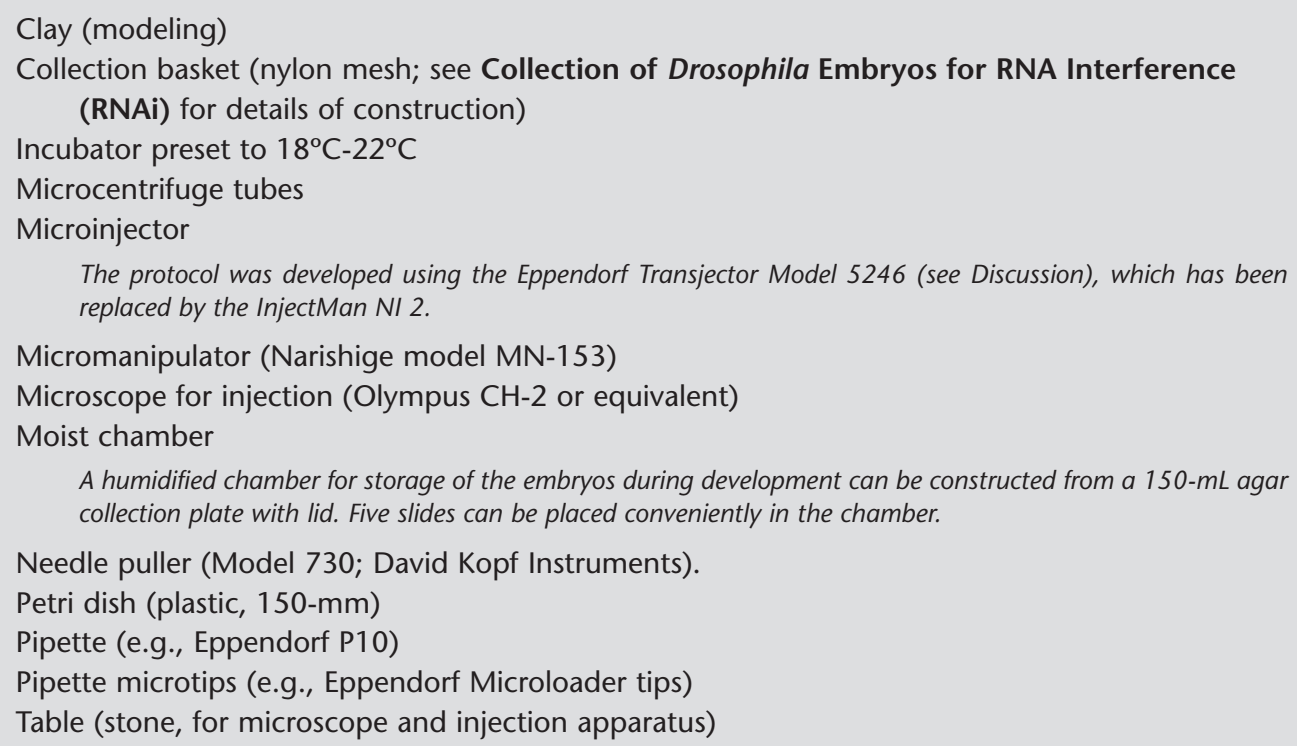

\section{METHOD}

\section{Preparing the Needles}

1. To pull the glass capillaries into needles:

i. Set heat at 12.5-13.0 and set the solenoid at 4 on the needle puller.

ii. Follow the manufacturer's instructions for pulling the needles.

iii. Store freshly-pulled needles horizontally, embedded lightly on a flattened narrow strip of modeling clay placed on the bottom of a 150-mm covered plastic Petri dish.

2. Use a pipette (e.g., Eppendorf P10) fitted with a microtip (e.g., Eppendorf Microloader tips) to back-load the injection needles with 0.5-1.0 $\mu \mathrm{L}$ of dsRNA mixed with filtered food dye.

\section{Calibrating the Transjector}

3. Set the Transjector to automatic injection.

4. Set the injection pressure (Po) to 450 .

5. Set the compensation pressure $(\mathrm{PC})$ to 570 .

6. Set the time of injections to $0.1 \mathrm{sec}$.

If using a different model injector, calibrate the injector according to the manufacturer's instructions.

\section{Injecting Embryos}

Based on the volume loaded into the needle (0.5-1.0 $\mu \mathrm{L})$, each embryo receives up to 100-200 pL of dsRNA. A typical loading, if the needle remains unbroken and unblocked, is good for the injection of approximately 1000 embryos or more. Inject the embryos in the posterior end, slightly off-center, because the posterior tip of the chorion is very hard and needles often break in this position. Keep the injection room at $18^{\circ} \mathrm{C}$ to slow development.

7. Break the filled needle against the edge of the slide containing the embryos to create a sharp point, as follows:

i. Move the slide slowly toward the needle tip while simultaneously depressing the "clean" button on the Transjector. 
ii. The moment that the slide lightly taps the tip and the tip breaks, a small amount of the dye will leak from the needle tip. Release the "clean" button.

Dye flow should stop when the "clean" button is no longer depressed. The sample is now ready for injection. If the tip is too large after breakage, the needle will continue to drip dye when the "clean" button is not depressed. Such tips will destroy the embryos during injection.

8. Bring the needle tip and the posterior tip of the embryo into the same focal plane. Make sure that the needle is positioned off-center with respect to the posterior tip of the embryo (see Fig. 1). For best results, inject the embryos with the needle at an angle slightly greater than $45^{\circ}$ relative to the embryo surface in the posterior quarter of the embryo.

9. Insert the needle just far enough to penetrate the vitelline membrane.

10. Inject the RNA into the embryo. A small amount of food dye will appear as a small dot in the posterior end of the embryo. It takes $\sim 1-5 \mathrm{sec}$ to inject each embryo.

11. After all the embryos on a slide have been injected, place the slide in a covered moist chamber at $18^{\circ} \mathrm{C}-22^{\circ} \mathrm{C}$ until embryogenesis is complete $(\sim 48 \mathrm{~h})$ or until the desired stage of development is reached.

\section{Collecting Injected Embryos for Analysis}

12. Wash the embryos off the slide into a nylon-mesh collection basket.

13. Transfer the embryos to a microcentrifuge tube.

14. Fix the embryos and stain them using standard protocols; see Ashburner (1989a,b).

\section{TROUBLESHOOTING}

Problem: The injection needle becomes blocked.

[Step 10]

Solution: To minimize capillary backflow and blockage, do not push the needle too far into the embryo; insert the needle just far enough to penetrate the vitelline membrane. If blockage should occur on the Transjector, immerse the needle tip in a drop of coverslip oil and hold down the "clean" button. When the needle clears, the food coloring will be visible in the oil. If blockage persists, change the needles.

Problem: Embryos fail to develop normally.

[Step 11]

Solution: Keep the embryos moist after injection. Punctured embryos need a humid environment or they tend to shrink and dry up. Note that excessive moisture (e.g., embryos floating in water) will also kill the embryos.

\section{DISCUSSION}

The microinjector we use is the Eppendorf Transjector. Although primarily used for the injection of cultured cells, the Transjector is easily adapted for the injection of Drosophila embryos directly through the chorion. Highly reproducible injection conditions can be defined with regard to the volume of material injected, while preventing backflow of material into the needle, which results in needle blockage. This is accomplished by varying the injection pressure, compensation pressure, and the time of injection. The Transjector was a key factor in being able to routinely inject approximately 500 embryos for each analysis. It also has a useful "clean button" that uses a burst of high-pressure air to clean the needle tip in case of blockage. This greatly reduces the number of times needles need to be changed.

In our studies, typical efficiencies for generation of the mutant phenotype in the embryo ranged from $72 \%$ to $86 \%$, but penetration of the white mutation to the adult eye was $<3 \%$ (Misquitta and Paterson 1999). RNAi has also been used in dechorionated embryos to demonstrate that both frizzled and frizzled 2 were in the wingless pathway (Kennerdell and Carthew 1998). However, dechorionated embryos have a much lower survival rate and injection artifacts are more pronounced. To rescue 

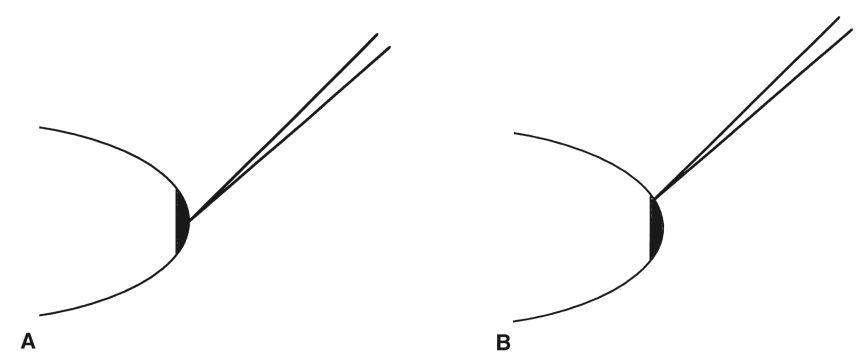

FIGURE 1. Correct injection position for the embryos. (A) Do not inject the embryos directly in the posterior center of the chorion, as the needles often break at this site due to the apparent increased hardness of the chorion. (B) Embryos are injected in the posterior end, slightly off-center, with much less needle breakage or blockage.

injected transgenic lines, apply a small amount of yeast paste to the slide and transfer the embryos from the paste to food vials. Recent experience has shown that using $<1 \mathrm{mg} / \mathrm{mL}$ of dsRNA for dsRNAs longer than $1 \mathrm{~kb}$ minimizes needle blockage while $1 \mathrm{mg} / \mathrm{mL}$ is suitable for dsRNAs shorter than $1 \mathrm{~Kb}$ in length.

\section{REFERENCES}

Ashburner, M. 1989a. Drosophila: A laboratory handbook. Cold Spring Harbor Laboratory Press, Cold Spring Harbor, NY.

Ashburner, M. 1989b. Drosophila: A laboratory manual. Cold Spring Harbor Laboratory Press, Cold Spring Harbor, NY.

Kennerdell, J.R. and Carthew, R.W. 1998. Use of dsRNA-mediated genetic interference to demonstrate that frizzled and frizzled 2 act in the wingless pathway. Cell 95: 1017-1026.

Kiehart, D.P., Crawford, J.M., and Montague, R.A. 2000. Quantitative microinjection of Drosophila embryos. In Drosophila protocols

(eds. W. Sullivan et al.), pp. 345-359. Cold Spring Harbor Laboratory Press, Cold Spring Harbor, NY.

Misquitta, L. and Paterson, B.M. 1999. Targeted disruption of gene function in Drosophila by RNA interference (RNA-i): A role for nautilus in embryonic somatic muscle formation. Proc. Natl. Acad. Sci. 96: 1451-1456.

Misquitta, L., Wei, Q., and Paterson, B.M. 2008. Drosophila RNA interference (RNAi) using a Gal-4 inducible transgene vector. CSH Protocols 10.1101/pdb.ip51. 


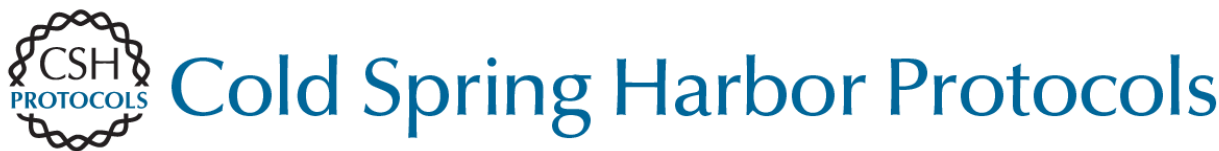

\section{Injection of dsRNA into Drosophila Embryos for RNA Interference (RNAi)}

\author{
Leonie Misquitta, Qin Wei and Bruce M. Paterson
}

Cold Spring Harb Protoc; doi: 10.1101/pdb.prot4918

\begin{tabular}{|c|c|}
\hline $\begin{array}{r}\text { Email Alerting } \\
\text { Service }\end{array}$ & Receive free email alerts when new articles cite this article - click here. \\
\hline $\begin{array}{l}\text { Subject } \\
\text { Categories }\end{array}$ & $\begin{array}{l}\text { Browse articles on similar topics from Cold Spring Harbor Protocols. } \\
\text { Cell Biology, general (1382 articles) } \\
\text { Developmental Biology (728 articles) } \\
\text { DNA Delivery/Gene Transfer (344 articles) } \\
\text { DNA Delivery/Gene Transfer, general (341 articles) } \\
\text { Drosophila (272 articles) } \\
\text { Drosophila Transgenics (39 articles) } \\
\text { Genetics, general (374 articles) } \\
\text { Laboratory Organisms, general (923 articles) } \\
\text { Molecular Biology, general (1293 articles) } \\
\text { Non-Viral Methods (226 articles) } \\
\text { Preparation of Macromolecules and Introduction into Cells (97 articles) } \\
\text { RNA Interference (RNAi)/siRNA (123 articles) } \\
\text { Transgenic Technology, general (187 articles) }\end{array}$ \\
\hline
\end{tabular}

